\title{
(2) OPEN ACCESS \\ Headshots on bidi and smokeless tobacco packs in India and Bangladesh: a curious branding element
}

\author{
Katherine C Smith (D) ${ }^{1,2}$ Kevin Welding (D) , ${ }^{2}$ Michael lacobelli, ${ }^{2}$ Sejal Saraf, ${ }^{2}$ \\ Joanna E Cohen (10) 1,2
}

${ }^{1}$ Bloomberg School of Public Health, Johns Hopkins University, Baltimore, Maryland, USA

${ }^{2}$ Institute for Global Tobacco Control, Johns Hopkins University Bloomberg School of Public Health, Baltimore, Maryland, USA

\section{Correspondence to} Dr Katherine C Smith, Bloomberg School of Public Health, Johns Hopkins University, Baltimore, Maryland, USA; kasmith@jhsph.edu
The appeal of smoking and specific brands has long been promoted through carefully crafted, aspirational characters that are highlighted in tobacco marketing. ${ }^{12}$ The Marlboro Man is the archetypal fictional character that associated smoking with aspirational personal and lifestyle attributes in order to promote a specific brand; ad campaigns for brands such as Newport and Virginia Slims routinely depicted aspirational people in product promotions. There is little published research on branding of other tobacco products popular in lowincome and middle-income countries.

During data collection for TPackSS (Tobacco Packaging Surveillance System $^{3}$ ) in India and Bangladesh, we noticed faces similar to headshots or passport photos as part of the branding on bidi and smokeless tobacco (SLT) packaging in a way that we did not see on cigarettes.

Following the TPackSS protocol, ${ }^{4}$ we systematically collected 572 unique bidi (India: 2013, 2016, 2017; Bangladesh: 2013, 2016) and smokeless (Bangladesh: 2016; India: 2016, 2017) packs. Data were collected prior to and following changes to health warning label policies in both countries.
Each pack was coded by two independent coders for presence of a headshot photo, and one coder subsequently noted key headshot features including apparent gender (men, women, unclear), age (adult or child), style of dress (traditional or western), number of pictures, whether picture is a drawing or a photo and colour of picture (colour or black and white).

Of unique packs purchased, $290 \quad(50.7 \%)$ included one or more headshot pictures: 121 bidi and 169 smokeless packs. Headshots were found on packs in all data collection waves, and we have previously reported on low compliance levels for the new health warning requirements, ${ }^{56}$ which may have left space for branding elements to continue. These headshots were often placed in the front and centre of the pack. Most packs with headshots included only one picture $(\mathrm{n}=158,54.9 \%)$, with a maximum on any pack being six; most $(n=212,73 \%)$ packs included at least one photograph. In most packs with more than one headshot, these were repetitions of the same picture. One pack had a headshot printed on individual bidi sticks.
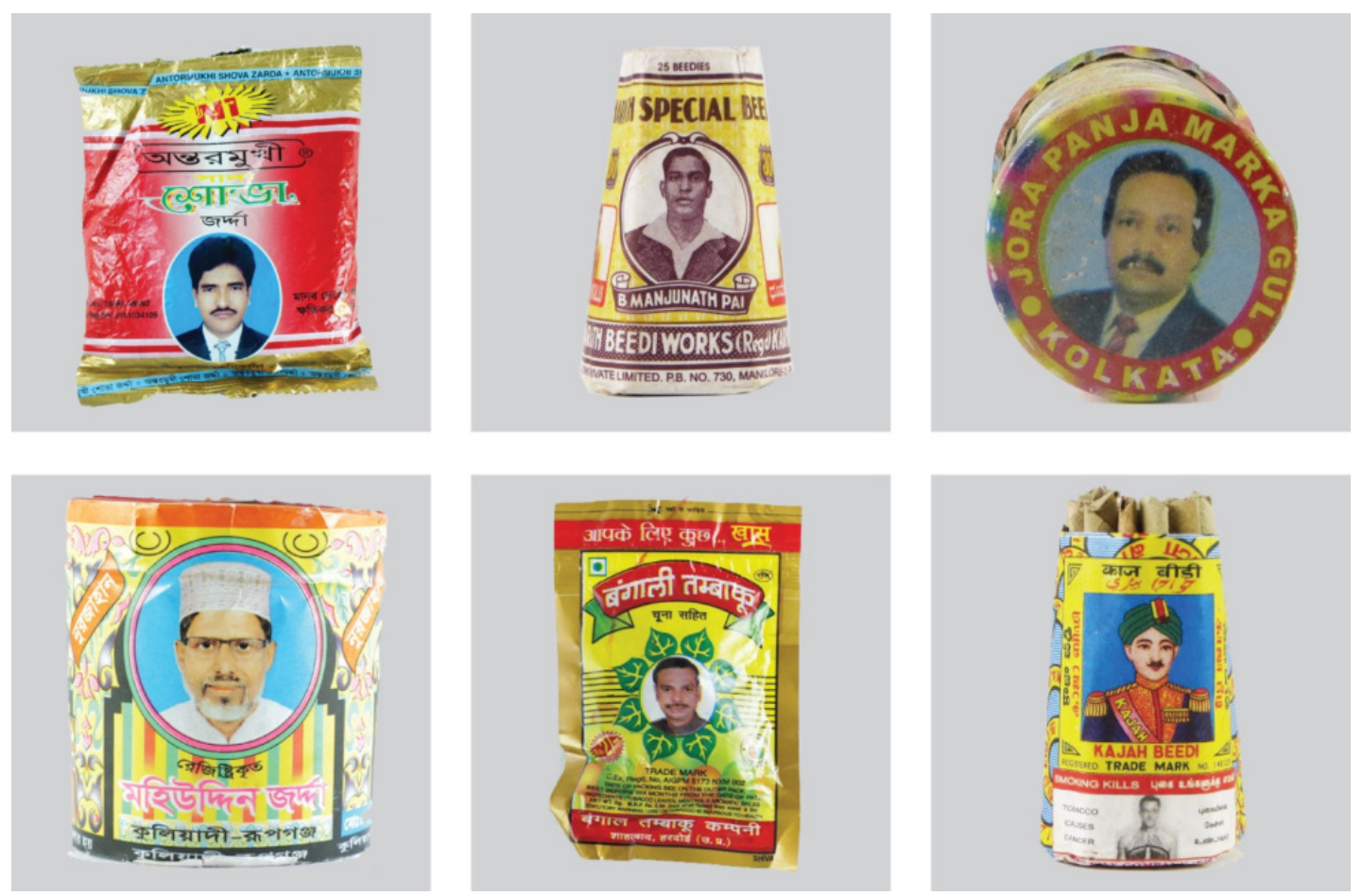

Figure 1 Illustrative packs with men's faces. Country, collection date, brand: (left to right top row): Bangladesh, 2016, Antormukhi; India, 2013, Bharath Special; India, 2016, Jora Panja Gul. (Left to right bottom row): Bangladesh, 2016, Mahiuddin; India, 2017, Bangali Tobacco; India, 2013, Kajah. 

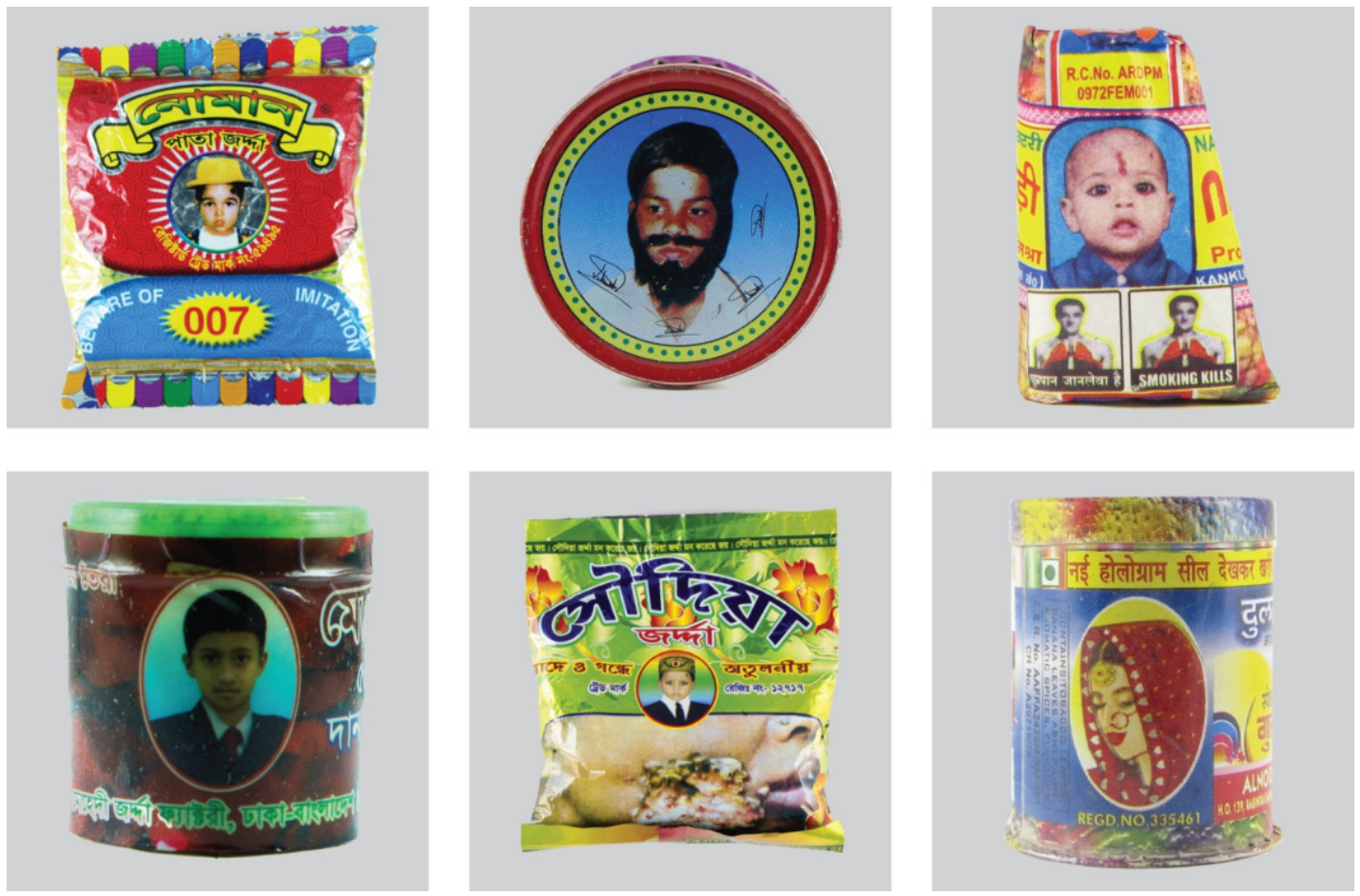

Figure 2 Illustrative packs with women, children and babies' faces. Country, collection date, brand (left to right top row): Bangladesh, 2016, Noman; India, 2017, Palang Tore; IIndia, 2013, Nano. (Left to right bottom row): Bangladesh, 2016, Mehede 555; Bangladesh, 2016, Soudia; India, 2016, Dulhan Gul.

The vast majority of packs included headshots of men $(n=258$, $88.9 \%)$, many of whom were dressed in western-style business wear (jacket and tie, and sometimes a hat), though there are also some photos of men in more traditional dress (figure 1). A minority of SLT packs $(n=17,10 \%)$ depicted women, never in western clothing, but rather drawings of women in bridal veils, other non-western attire or female deities. Almost all (16 of 17) depictions of women were drawings. It is also notable that depictions of women were always in profile or semi-profile, with eye gaze downwards, which was distinct from the men's pictures. Finally, there were also headshots of children (seemingly boys) and infants $(\mathrm{n}=24,8.3 \%)$ on packages (figure 2$)$. Interestingly, there was one headshot of a boy with a drawn-on beard (top middle of figure 2).

We have found no literature as to how such faces serve a branding strategy for bidi and smokeless tobacco in this context. These depictions may be factual (it may be that the picture is of the owner of the company who made this product), or aspirational (the photo may depict the type of person who would use it), or both. The faces may serve as a form of informal trademark. Nevertheless, we argue that it is inappropriate to use depictions of potentially aspirational or evocative figures, especially deities, children and babies, to promote any tobacco product, and that this practice should be prohibited in future marketing and packaging restrictions.

Acknowledgements We would like to acknowledge and Dr Sarah Besky and our TPackSS in-country partners in Bangladesh and India (detailed on our website https://www.globaltobaccocontrol.org/tpackss/about) for their contributions to this work.

Contributors All authors have contributed to the collection, analysis and writing related to the work presented. All have read and approved the submitted version of the work. The photos included in our figures were taken by the study team, and sit on our TPackSS website. We do not need any additional permission to use these images.

Funding This work was supported with funding from Bloomberg Philanthropies' Bloomberg Initiative to Reduce Tobacco Use (Bloomberg.org).

Competing interests None declared.

Patient consent for publication Not required.

Provenance and peer review Not commissioned; externally peer reviewed.

Open access This is an open access article distributed in accordance with the Creative Commons Attribution Non Commercial (CC BY-NC 4.0) license, which permits others to distribute, remix, adapt, build upon this work non-commercially, and license their derivative works on different terms, provided the original work is properly cited, appropriate credit is given, any changes made indicated, and the use is non-commercial. See: http://creativecommons.org/licenses/by-nc/4.0/.

\section{ORCID iDs}

Katherine C Smith http://orcid.org/0000-0003-2140-1690

Kevin Welding http://orcid.org/0000-0002-1833-6691

Joanna E Cohen http://orcid.org/0000-0002-3869-3637

\section{REFERENCES}

1 Novelli WD. "Don't smoke," buy marlboro. BMJ 1999;318:1296.

2 White C, Oliffe J, Bottorff J. From the physician to the Marlboro man: masculinity, health and cigarette advertising in America, 1946-1964. Men Masc 2012;15:526-47.

3 Institute for Global Tobacco Control. TPackSS: tobacco packaging surveillance system. Available: https://globaltobaccocontrol.org/tpackss/

4 Smith K, Washington C, Brown J, et al. The tobacco pack surveillance system: a protocol for assessing health warning compliance, design features, and appeals of tobacco packs sold in low- and middle-income countries. JMIR Public Health Surveill 2015;1:e8.

5 Saraf S, Welding K, Cohen JE, et al. Compliance of health warning labels on smokeless tobacco products in India. Paper presented at: The Society for Research on Nicotine \& Tobacco Annual Meeting; February 21-24. Baltimore, Maryland, 2018.

6 Saraf S, Welding K, Cohen JE, et al. Assessment of health warning label compliance on bidi packages in five states in India. Poster presentated at: The 50th Union World Conference on Lung Health; November 1, 2019. Hyderabad, India. 